Open Access

\title{
Big data management skills: accurate measurement
}

\author{
Elspeth McKay ${ }^{* *}$ and Marlina Binti Mohamad²
}

\author{
* Correspondence: elspeth.mckay@ \\ rmit.edu.au \\ ${ }^{1}$ RMIT University, School of Business \\ Information Technology and \\ Logistics, GPO Box 2476, Melbourne, \\ VIC 3000, Australia \\ Full list of author information is \\ available at the end of the article
}

\begin{abstract}
Some say that big data is transforming business and society. This can mean widereaching disruption for commerce, health and world governance. Few authors agree on what constitutes big data, depending on the philosophical stance taken. Our propensity for keeping data archived is posing major issues globally, with retrieval and application of such data crossing ethical boundaries. However, one of the more pressing issues is the growing need for confirming whether those working with such big data have the required digital skills to cope. This paper presents one effective and efficient way to identify such digital skill acquisition. We show the progression from the earlier approach used for measuring proficiency between novice and experienced programmers using traditional statistical measures, to adopting a more comprehensive unidimensional scale that empowers comprehension of human performance and test-item performance relative to each other. This methodology offers an effective tool for understanding of individual differences in digital skill development.

Keywords: Big data management skills, Digital skills development, Cognitive performance measurement, Instructional design, Human-computer interaction, Item response theory, Rasch model
\end{abstract}

\section{Review}

\section{Introduction}

There is no surprise that big data is now receiving considerable attention, especially from the business community (Marr 2016a), where astute entrepreneurs are led to believe they can capitalise on such data to improve their commercial activities. The emerging awareness that is bringing forward a plethora of views from all corners of the digital spectrum has been facilitated by the spread of wireless communication (Alsharif and Nordin 2017). Consequently, there are various opinions of how to define big data. On the one hand, high-end technologies combine information decision-making along with analytic perception gained from examining data through sophisticated technologies that reveal insights from combinations of diverse data sources (Marr 2016b). Others believe the term describes analysis of messy data and use the term to describe the process of finding patterns of data behaviour amongst the conceptual messiness (Melendez 2015; Schöch 2013). While another view identified 10 characteristics of big data that reveal non-linear interrelationships through a three level framework: fundamental (volume, velocity, variety and veracity); technological (intelligence, analytics,

(c) The Author(s). 2018, corrected publication June/2018. Open Access This article is distributed under the terms of the Creative Commons Attribution 4.0 International License (http://creativecommons.org/licenses/by/4.0/), which permits unrestricted use, distribution, and reproduction in any medium, provided you give appropriate credit to the original author(s) and the source, provide a link to the Creative Commons license, and indicate if changes were made. 
and infrastructure); and socio-economic (service, value and market) (Sun 2018). These characteristics require high-level digital skills to manage the information communications technology (ICT) tools involved (Hartley 2003).

Therefore it does seem natural to link human informational wants and needs to large data sets; to this end, the healthcare industry has acquired a strong presence, where computational analyses can reveal previously unnoticed patterns, trends and associations (Farrington 2016). For example, the recent increase in wearable technologies has enabled collection of health-related real-time data that can be linked to historical records and stored for later retrieval by individuals, healthcare workers and government agencies. Consequently, investment in information technology (IT) to manage and maintain such big data collections is increasing rapidly (Tambe 2014).

The main purpose of this paper however is to show that over time, the methods for measuring people's digital skills has evolved from taking a classical test theory (CTT) approach to using a more comprehensive Rasch item response theory (IRT) assessment model.

CTT typically uses common statistical analyses to provide information that relates to the reliability of the test score. For instance, according to Adams and Khoo (1996) this means counting the number of people providing a response to a test-item, calculating the percentage of total number of valid responses and generating the Pt-biserial that shows the correlation between a response type and the total raw score achieved on the test and the p-value that represents the significance of that correlation. In contrast, the Rasch IRT enables a finer grained analysis that measures the relative performance of each test-item and the relative performance of the individuals taking the test on a unidimensional scale (Bakkar 2016).

As mentioned before, this paper presents the changing ways researchers have determined whether an individual is capable of such problem-based (digital) reasoning (Mohamad 2012) in a higher education (HE) institutional setting. To this end there are three separate research studies presented here. Although each study shared a common desire for measurement of a particular digital skill, the objective of each study was to answer a specific research question. In this paper, we are proposing that it is particularly important to differentiate what an individual might know from what they might not (McKay and Izard 2015). Therefore, criterion-referenced testing is an effective way to measure performance according to the pre-specified criterion (Griffin and Nix 1991). Hence this paper describes two such experimental studies to reveal that the Rasch IRT model is the best tool to examine such data (Bond and Fox 2015).

Notwithstanding this, the main consideration is whether people in general have the necessary digital skills (Van Laar et al. 2017) to take advantage of the seductive promises that surround the advent of big data. Accordingly, there has been a growing body of literature concentrating on the need for such digital literacy that hitherto encompassed human-computer interaction (HCI) (McKay 2008) through the machine-dimension (technical requirements) and the human-dimension (social interaction). There has been further interest in defining computer literacy (Mat-Jizat 2012) where an emphasis was placed on the researcher to know how to assess an individual's digital skills. One such contribution to support Mat-Jizat (2012) has been from the 
Digital Skills Academy in Dublin (Digital Skills Academy launches online degree in integrated digital technology, business, design 2015), from which graduates were welcomed by top IT organisations in many countries (Hepburn 2013).

And so, we will commence the discussion for this paper on digital skill development that used problem-solving skill development using abstract programming concepts, with a study that took a traditional classroom approach to determine differences between novice and experienced learners who were trying to acquire computer programming skills (Bagley 1990; Tennyson and Bagley 1991). The study was using CTT to measure the effects of paper-based instructional strategies and subsequent digital knowledge acquisition assessment in the form of problem solving ability in an introductory programming course. We then present the McKay (2000a) study, which used portions of the Bagley (1990) study as the foundation to investigate the interactive effects of such paper-based strategies (text-plus-textual metaphors/text-plus-graphical metaphors) and cognitive style preferences on the learning outcomes (problem solving), using the Rasch IRT cognitive measurement model. The McKay (2000a, 2000b) work was then taken up by Mohamad (2012) to investigate the instructional strategies in an online/digital context, also using the Rasch IRT model.

The novelty of this research is the application of the Rasch IRT model to identify a digital skills development framework.

\section{Study-1: Problem-solving abstract concepts}

In keeping with the Sun (2018) stance on big data characteristics and the non-linear interrelationships through the 'technological framework' (intelligence, analytics, and infrastructure), the Bagley (1990) study represents the initial instructional design (ID) pedagogy that was used to underpin other IS-doctoral theses (Alwi and McKay 2012; Bakkar 2016; Barefah and McKay 2016; McKay 2000a; Mohamad 2012). Digital skill development was a common pedagogy focus for each of these theses. This paper proposes that such digital skills development is a key attribute for dealing with big data management, earlier described by Sun (2018) as the 10 big characteristics. The Bagley thesis was entitled 'Structured Versus Discovery Instructional Formats for Improving Concept Acquisition by Domain-Experienced and Domain-Novice Adult Learners.' The purpose of this research was to investigate the interaction of instructional strategies with students that had no prior domain knowledge of computer programming, on the assumption that learners with no such knowledge would learn programming concepts better with a structured strategy versus those who had to construct the necessary conceptual knowledge (Tennyson and Bagley 1991 p.2) The Bagley research involved paper-based self-paced instructional booklets (structured format/discovery format) that commenced with a brief review of the introductory material, which then led the students through the instructional strategy.

There was expository content for each learning goal, such as: definitions; best example; and a range of other examples; non-examples; and worked examples of problems, according to the ID principles for learning abstract concepts (Merrill et al. 1992).

The structured instructional booklet involved three lessons: data types; program structure and three PASCAL statements (Readln, Writeln, and assignment) and writing 
new PASCAL programs. The discovery booklet involved four parts: basic PASCAL programs (with sample data); three problem statements (with input, output, and the algorithmic process); pseudocode example; three problem statements.

\section{Self-paced instructional booklets for the exploratory study}

In the structured instructional booklet, the initial directions were to proceed through the three lessons to learn about basic PASCAL programming; in the discovery instructional booklet, learners were encouraged to discover the solutions to the problems using their past knowledge or relevant content provided in the structured booklet.

The learning content reflected the problem-solving programming conventions of the time for developing algorithms and pseudocode (or structured-English statements). This instructional material involved: sequence, selection and repetition logic patterns (or programming control structures). The generic textual instruction was designed to guide learners through progressively more complex content (Bagley 1990). Following the expository learning content there was a four-page interrogatory section that lead the learner through the instructional material and to complete the programming problems. Intentional instructional gaps were left in the practice examples to encourage the learner to write parts of the algorithms on their own. The intention of the strategy was for the learner to gradually create more of the algorithm, with less information given as the task progressed. This was known as a fading technique and according to Bagley (1990) was shown to be more successful for novice programmers than for experienced programmers.

Instruction commenced with a description of an algorithm. Then the learners were guided by an epitome statement that gave the instructional goals and objectives for each sub-lesson, relating to four sub-lessons (McKay 2000a):

- logic patterns: (sequential, repetition, and conditional control structures)

- repetition logic: (using the DOWHILE and the REPEAT .. UNTIL structures)

- comparison of the two logic patterns

- example problems

Following the last example problem, a short review or summariser of the four sub-lessons was given, followed by an expanded epitome statement, devised to lead the learner to the next part of the lesson. Then there were two example problems that were fully explained in the instruction, including:

- an objective (setting out the expected instructional outcome)

- the situation description (setting the scenario context)

- the task description that involved a six-point suggested solution.

\section{Procedural knowledge development strategy}

Procedural knowledge provides the pathway to the instructional outcome, which in this case is to write an algorithm that represents the digital solution for solving a particular problem. For example: 
- redefine the problem (in terms of input/processing/output)

- logic patterns (control structures required to support the solution)

- the repetition question (most novice-programmers were unaware of the need for conceptualising this component)

- repetition starting point (once again novice-programmers found this difficult)

- repetition conditional statement

- alternate repetition condition

- a suggested solution algorithm

To reinforce the declarative, procedural and conceptual knowledge (Bagley 1990), example problems were followed by two more practice problems. Declarative knowledge relates to the description of things, events or processes and their associated relationships; procedural knowledge relates to knowing how to perform the necessary tasks; conceptual knowledge requires an understanding of the explicit/implicit principles involved. The learning task section was presented as an interrogatory learning format (McKay 2000a p.164). Suggested solutions were given for the first practice problem (McKay 2000a p.172). However, in the second practice problem, the final task of writing a complete solution algorithm was left blank for the participant to finish; hence "leaving gaps in this manner provides learners with an opportunity to practise their declarative knowledge" (McKay 2000a p.171). By working through the problem examples, participants could check their procedural and conceptual knowledge against the suggested solutions. This technique was known as a coaching technique, which pointed out key issues relating the problem to the definition, best examples, and non-examples, according to Bagley (1990).

\section{Research design}

This study involved a $2 \times 2$-factorial design to test the independent variables: prior knowledge and instructional format (structured/discovery), to test novice and experienced adult learners' computer programming knowledge acquisition. A Wechsler Adult Intelligence Scale (WAIS) arithmetic reasoning test was given to all learners prior to the start of the experiment; the results were used as a covariate to determine whether arithmetic reasoning might affect the pre-test (a screening test for prior computer programming knowledge) and the post-test (to determine level of change in knowledge acquisition).

\section{Methodology}

There were 120 students who were randomly assigned to four treatment groups (novice or experienced programmers:structured instructional format; novice or experienced:discovery instructional format). Novice programmers were deemed as having no prior knowledge of any computer programming language, while the experienced programmers had a minimum of one computer programming course in BASIC. The dependent variables were the correct scores achieved on the post-test. Analysis of variance (ANOVA) was used to analyse the results.

\section{Results}

Overall the Bagley (1990) results confirmed two hypotheses: (1) that given a structured instructional format, students with no prior knowledge of computer programming 
improved their learning of computer programming; and (2) that giving a discovery instructional format to students who did have prior computer programming knowledge did improve their learning of a new computer programming language. Yet the differences in the results when considering the interactive effect of instructional strategy and prior domain knowledge (experienced/novice) on performance outcomes revealed that given the structured instructional format, the experienced learners did not perform as well. And, when given the structured instructional format, the novice programming learners who would not be using any relevant prior knowledge, outperformed the experienced learners given the same treatment.

\section{Discussion}

These instructional strategies provided a general insight into how researchers investigated the acquisition of problem-solving skills to solve abstract problems (and more specifically for writing computer programs). At the time of this study, and long before the concept of big data was conceived, researchers were using the term 'computer literacy' to describe the $\mathrm{HCI}$. Then, the research focus was mainly on the cognitive processing styles (structured/discovery) and peoples' capabilities expressed as arithmetic reasoning (problem-solving) abilities. We maintain that it was the advent of Web 2.0 and the introduction of more powerful computers that has advanced the installation of our big data platforms, and has refocused educational researchers' view of how to prepare effective instructional strategies to enhance the digital skills development that is necessary to deal with such big data.

\section{Study-2: Paper-based instructional metaphor format and cognitive style}

Through the 1990's researchers were looking at ways to individualise instructional materials; while at the same time computer systems were affording easier adoption of graphical content to provide people's informational needs. In support of this assertion, the McKay (2000a) study drew on the Bagley (1990) work to include an investigation of the interactive effects of instructional format involving textual/graphical metaphors and cognitive style (McKay 2000a p.78) for the acquisition of introductory programming/ problem-solving techniques.

Again, and in keeping with the Sun (2018) stance on big data characteristics and the non-linear interrelationships through the 'technological framework', described as intelligence (often referred to as artificial intelligence) and data-driven analytics involving collection, organising to discover visual patterns (to support decision making) (Sun 2018 p.5); this research presented a novel approach for dealing with the cognitive assessment. To this end, the researcher investigated the interactive effects of instructional mode (text/graphical metaphors) with a student's individual cognitive instructional preference (verbal/imager). It is further proposed here that these personal instructional characteristics may have some bearing on an individual's ability to deal with the high-level nature of the digital skills that are necessary to manage big data. The research involved pursuing the following question in a paper-based experimental context: does the interaction of instructional format and cognitive style construct affect the acquisition of abstract programming concepts?

As described in more detail in McKay (2000b), cognitive style has been categorised as wholist-analytic and verbal-imager where the cognitive continua form an integrative 
model of cognitive style (Riding and Rayner 1998). Figure 1 shows this cognitive style model, which can identify an individual's position on both orthogonal continua, according to Riding (1993). And so, an individual's position on one dimension is independent of their position on the other (Riding 1993). Accordingly, the wholist-analytic dimension describes whether an individual tends to process information in wholes or parts, while the verbal-imager dimension describes whether an individual is inclined to represent information verbally or visually during thinking.

The McKay (2000a) study reduced the Bagley (1990) content to concentrate solely on the programming logic patterns that would be teachable in a one-hour practical tutorial session. There were three paper-based instructional booklets used by groups of participants. As pre-instructional material, the first self-paced booklet was used by all the participants, and contained the preliminary expository instructional content as an introduction to computer programming (Fig. 2). The second and third booklets were designed in conjunction with the experiment to examine the interactive effect of instructional format: text-plus-textual metaphor (T1 Fig. 4) or text-plus-graphical metaphor (T2 Fig. 5) programming solution metaphors in terms of declarative, procedural and conceptual knowledge (Fig. 6).

In order to write a computer programme to solve (in a digital sense) a particular problem, Fig. 2 shows the complete task hierarchy as: entry level skills; problem solving skills; knowledge of (digital) rules, and basic computer literacy. The entry level skills defined here as problem solving skills, include such tasks as: being able to read and redefine the problem, then identifying the data-input, and the (digital)-processing necessary to achieve the data-output. The McKay (2000a) research concentrated on the problem-solving skills component of Fig. 2 to situate the instructional strategies for writing pseudocode for the algorithm.

Figure 3 provides an example of how the instructional strategy conveyed the expository information for expressing the control flow statement known as a 'do while loop.'

The textual metaphors (Fig. 4) were used to expand Bagley's expository instructional strategy. In so doing, they articulated the critical attributes of the concept-to-be-learned

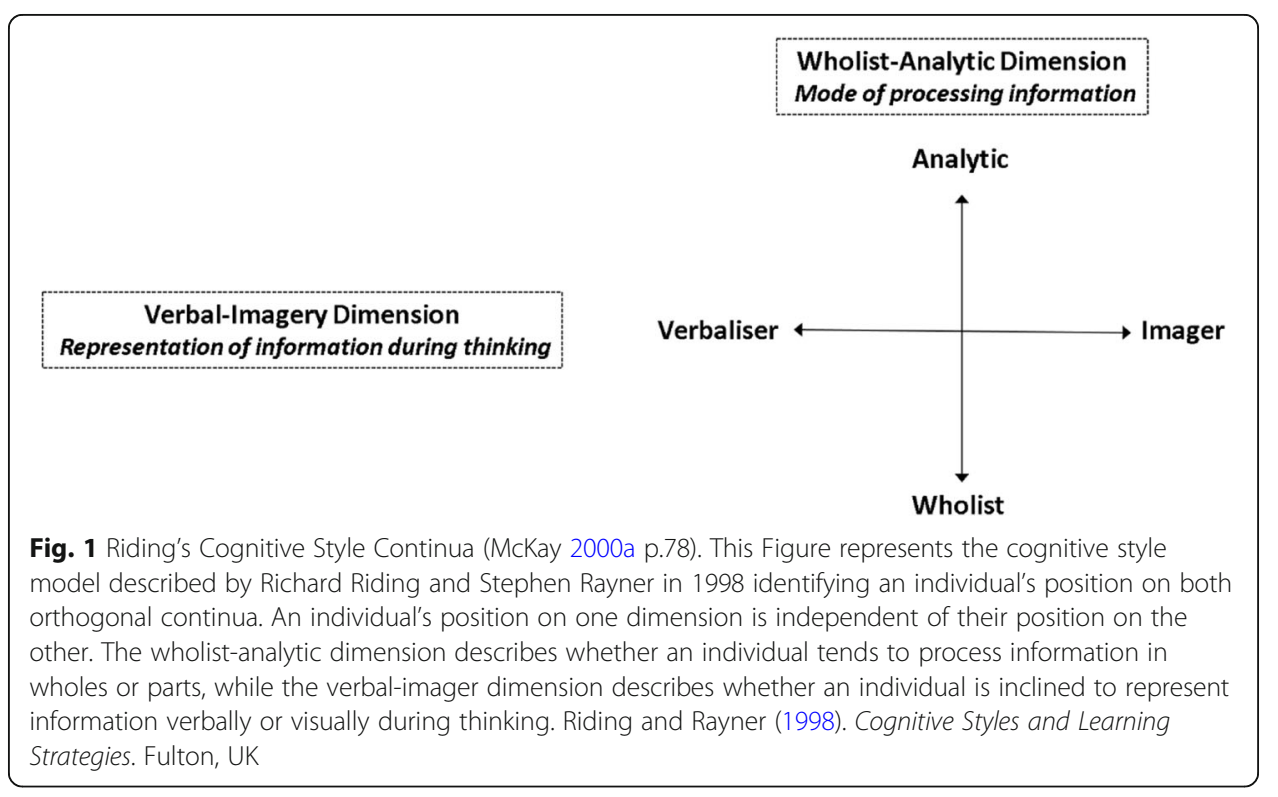




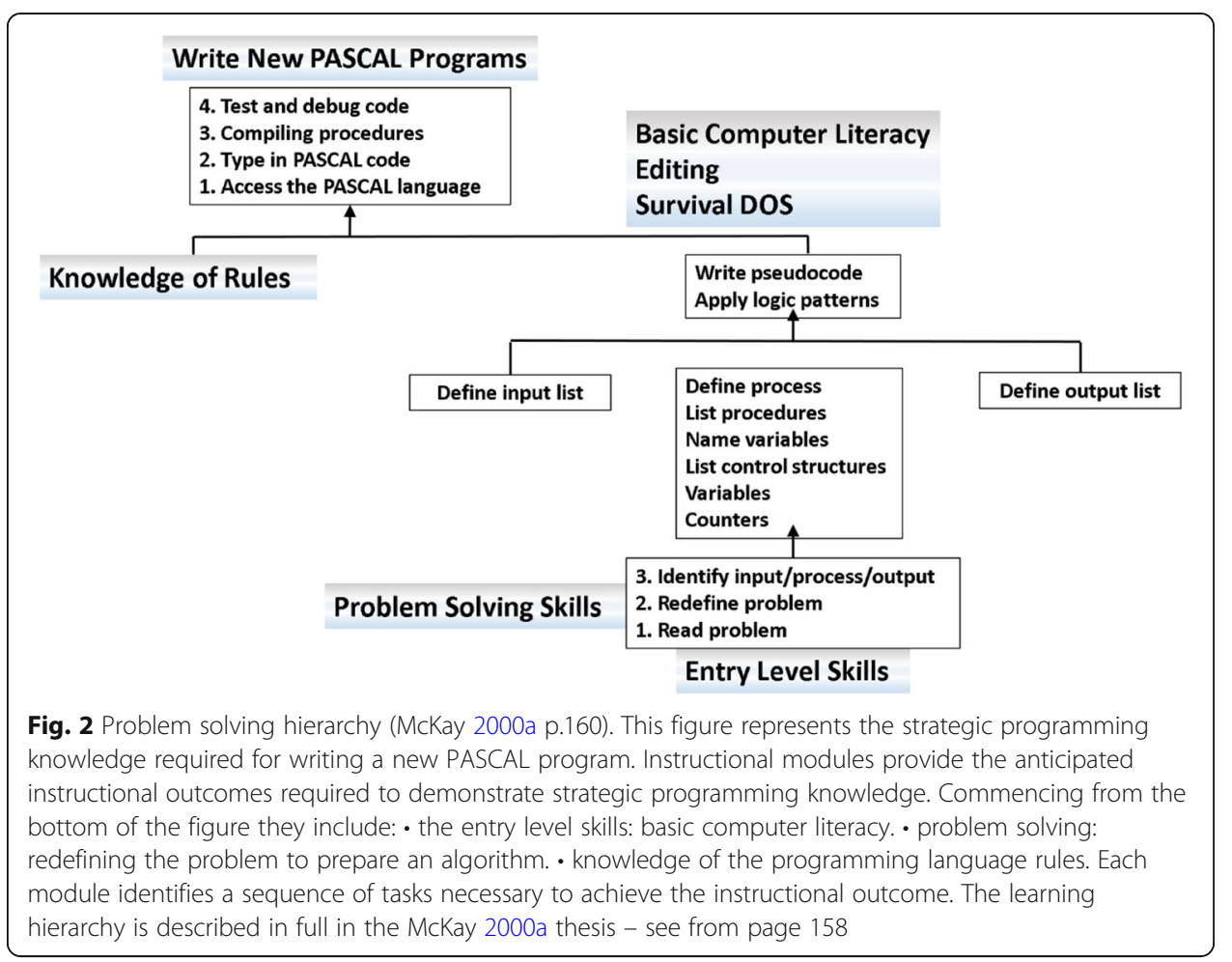

according to the first principles of instruction (Merrill 2009). In most cases, the textual metaphor was used after the generic textual description.

With the text-plus-graphical metaphor instructional treatment, the instructional format involved the same lesson on programming logic patterns as the text-plus-textual metaphor format booklet. However, the textual metaphor was replaced with a graphical representation (Fig. 5). The graphics were selected to represent the textual metaphors and chosen by their commonly recognisable and distinguishing (or salient) features.

A 'test instrument specification matrix' was devised to design the test-items that would be used to determine the expected introductory programming knowledge acquisition. The horizontal axis was used to depict the instructional objectives, with the vertical axis used for the programming content (or learning domain). As shown

\section{There are two important considerations about which you must be aware before designing a DOWHILE loop.}

Firstly, the testing of the condition is at the beginning of the loop. This means that the programmer may need to perform some initial processing to adequately set up the condition before it can be tested.

\section{Secondly, the only way to terminate the loop is to render the DOWHILE condition false. This means you must set up some process within the statement block which will eventually change the condition so that the condition becomes false. Failure to do this results in an endless loop.}

Fig. 3 Common expository instructional format (McKay 2000a p.163). This figure represents an example of an instructional strategy that provides key information of a programming control flow statement - known as a 'do while loop.' It is showing the testing condition and the procedure for dealing with a condition that has become false 


\section{City Loop tram circuit algorithm \\ DOWHILE $>=8 \mathrm{am}$ and $<=6 \mathrm{pm}$ \\ Tram leaves Flinders street depot at 8 am to pick up passengers \\ Tram travels on city loop to pick up and/or set down passengers \\ Add number of passengers picked up by City Loop Tram to daily list ENDDO \\ Print total number of passengers using City Loop Tram Service daily \\ END}

Fig. 4 Text-plus-textual metaphor (T1) - repetition programming logic (McKay 2000a p.165). This figure represents a textual metaphor for a 'do while loop'

in more detail in the McKay (2000a) thesis, the programming of such logic patterns was defined as a significant subdivision of programming skill. The learning domain is shown here (Fig. 6) as a continuum, beginning with simple programming concepts at one end, developing into more complex conceptual programming tasks at the other. There were nine-categories of digital skill identified along this continuum. The instructional objectives consisted of two-categories of specific programming knowledge.

Declarative knowledge was divided into two-levels of skill (McKay 2000a p.174-175):

1. verbal information: (knowing isolated rules)

2. intellectual: (knowing how to discriminate between concepts and principles)

The procedural knowledge, was divided into three-levels:

1. intellectual skill: (higher-order-rules for problem solving)

2. cognitive strategy: (recognising sub-tasks)

3. ability to integrate learning across learning domains:(for implementing a comprehensive plan of action)

\section{Repetition condition statement}
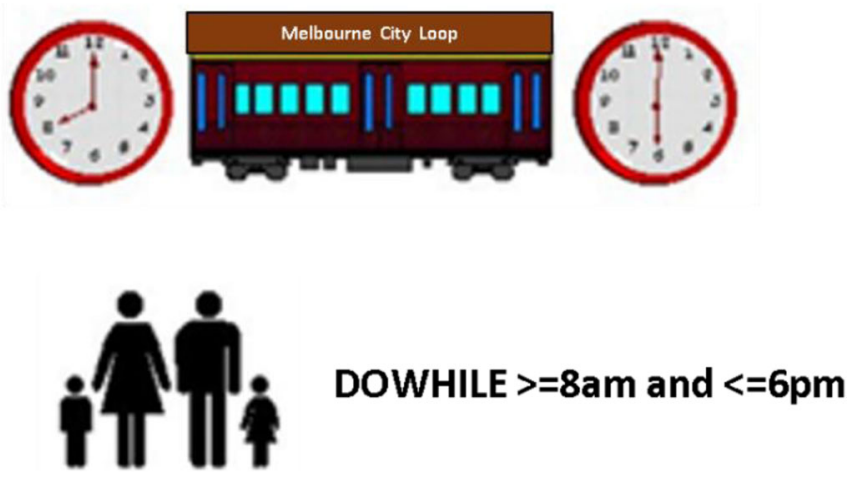

Fig. 5 Text-plus-graphical metaphor (T2) - repetition programming logic (McKay 2000a p.165). This figure represents an example of a text-plus-graphical metaphor for a 'do while loop' 


\begin{tabular}{|c|c|c|c|c|c|c|c|}
\hline & & \multicolumn{5}{|c|}{ Instructional Objectives : Programming Knowledge } & \\
\hline & & \multicolumn{2}{|c|}{ Dedarative } & \multicolumn{3}{|c|}{\begin{tabular}{|c|} 
Procedural \\
\end{tabular}} & \\
\hline & & Band-A & Band-B & Band-C & Band-D & Band-E & \\
\hline & & \begin{tabular}{|c|}
$\begin{array}{c}\text { Verbal } \\
\text { information } \\
\text { skill }\end{array}$ \\
\end{tabular} & $\begin{array}{c}\text { Intellectual } \\
\text { skill }\end{array}$ & $\begin{array}{l}\text { Intellectual } \\
\text { skill }\end{array}$ & $\begin{array}{l}\text { Cognitive } \\
\text { Strategy }\end{array}$ & $\begin{array}{l}\text { Cognitive } \\
\text { Strategy }\end{array}$ & \\
\hline & & Concrete concept & Basic rule & Higher-order-rule & Identify sub-tasks & Knowing the 'how' & \\
\hline & & Knows basic terms & Discriminates & Problem solving & \multirow{2}{*}{$\begin{array}{l}\text { Recognizes } \\
\text { unstated } \\
\text { assumptions }\end{array}$} & \begin{tabular}{|c|} 
Recall simple \\
prerequisite rules \\
$\&$ concepts \\
\end{tabular} & \\
\hline & & Knows 'that' & $\begin{array}{l}\text { Understands } \\
\text { concepts \& } \\
\text { prindiples }\end{array}$ & \begin{tabular}{|c} 
Applies concepts \& \\
principles to new \\
situations
\end{tabular} & & $\begin{array}{c}\text { Integrates learning } \\
\text { fromdifferent areas } \\
\text { into a plan for } \\
\text { solving a problem }\end{array}$ & \\
\hline Task No: & $\begin{array}{l}\text { Learning } \\
\text { Domain: }\end{array}$ & & & & & & Totals: \\
\hline 9 & $\begin{array}{c}\text { Solution } \\
\text { algorithm }\end{array}$ & & & & & & \\
\hline 8 & $\begin{array}{c}\text { Conditional } \\
\text { logic }\end{array}$ & & & & & & \\
\hline 7 & $\begin{array}{c}\text { Until logic } \\
\text { characteristic }\end{array}$ & & & & & & \\
\hline 6 & $\begin{array}{c}\text { While loop } \\
\text { characteristic }\end{array}$ & & & & & & \\
\hline 5 & $\begin{array}{c}\text { Repetition } \\
\text { question }\end{array}$ & & & & & & \\
\hline 4 & \begin{tabular}{|l|} 
Logic patterns \\
\end{tabular} & & & & & & \\
\hline 3 & $\begin{array}{c}\text { Basic } \\
\text { mathematics }\end{array}$ & & & & & & \\
\hline 2 & $\begin{array}{c}\text { Programming } \\
\text { process }\end{array}$ & & & & & & \\
\hline 1 & $\begin{array}{l}\text { Defining } \\
\text { diagram } \\
\end{array}$ & & & & & & \\
\hline & Totals: & & & & & & \\
\hline
\end{tabular}

\section{Validating the learning content}

Learning content validity testing was performed on the pre-test instrument and confirmed by independent content specialists. To determine scoring range for levels of prior domain knowledge, variance on the pre-test was established in a pilot study: a pre-test score of $<28 \%$ for novice-programmers, while the experienced-programmer group's score was recorded as $=>28 \%$ from the data obtained. The lower reliability recorded by the experienced-programming group was related to the higher pre-test scores, reflecting less change between the pre and post-test scores. These pre-test results supported the Bagley (1990) thesis. Accordingly, the pre-test met the original objective of dividing the learners who passed the pre-test after taking a programming course, and were, therefore, considered experienced-programmers (McKay 2000a p.171). At the core of this methodology was the initial instrument validation process which must be followed to ensure there was internal consistency and that a reliable measurement scale had been established. This means that the researcher must ascertain that test-items were a fit of the Rasch IRT model, which is discussed in more detail further on in this paper.

\section{Research design}

The experiment employed a $2 \times 2$ factorial design. As the extent of a design effect was unknown, simple random sample statistics were not used. Since the research questions 
were interested in the magnitude of effect, ANOVA was considered inappropriate (Izard 1999), and the Cohen (1977) approach was used instead. The Riding and Cheema Cognitive Styles Analysis (CSA) test was conducted before the experiment, so the researcher used another statistical measurement tool that was better suited to analyse the test data for the digital skills' performance (McKay 2000a p.183). This tool was the QUEST interactive test analysis system (Wu and Adams 2007), which uses both classical test theory (CTT) and the Rasch model known as the item response theory (IRT) (Griffin and Nix 1991), to evaluate the digital skill development and the test-item behaviour on a unidimensional probability scale (Bond and Fox 2015).

\section{Methodology}

There were 195-participants enrolled in a HE Business IS Computing course who completed the instructional treatments and cognitive assessment. The research schedule involved the participants in a five-stage process, including: registration and consent to participate; undertaking the CSA (the resulting CSA-ratio was used to allocate instructional treatment); a pre-test (to determine their prior domain knowledge); the instructional treatment (T1 or T2); and a post-test (that was used to determine the level of change in knowledge (digital skills acquisition)).

\section{Data analysis}

The data analysis was conducted using the QUEST measurement tool (Adams and Khoo 1996), while the digital skills acquisition was evaluated in terms of the magnitude of change in participant proficiency (magnitude of effect size as defined by Cohen's statistical power analysis (Cohen 1977)). QUEST allows for improved analyses of an individual's performance relative to other participants (McKay 2000b), and relative to the test-item difficulty. On the left side of Fig. 7, each participant or 'case' is depicted by an ' $x$ ', and the test-items are shown on the right-side of the map. The Rasch IRT estimates the probability of an individual making a certain response to a test-item (McKay and Izard 2015).

The QUEST Item Fit Map (Fig. 8) provides a visual check of magnitude of the fit statistic for the test-items. Overall, these test-items fit the Rasch model (Bond and Fox 2015), with the exception of test-item 34, which 'overfitted' the Rasch model because it fell outside of the left-hand vertical dotted line, indicating a mean square that was $30 \%$ below its expected value. Each test-item had been designed to test for specific types of digital programming skill/knowledge. In general, the higher the programming knowledge required to correctly answer a question, the higher on the logit scale the test item will appear.

Looking at Fig. 7 it is apparent that this pre-test was relatively easy for $85 \%$ of the participants, and more difficult for the remaining $15 \%$, who were able to answer the first part of test-item 9 but would struggle to achieve Test Item 1, 2 and the rest of the instrument.

\section{Results}

The final results revealed that the verbalisers (measured using the Riding and Cheema (1991) CSA tool) performed best when given the instructional format enhanced with graphical metaphors, and that some imagers may respond better with text-only material. Furthermore, when describing the interactive effects of the inherent mode of 


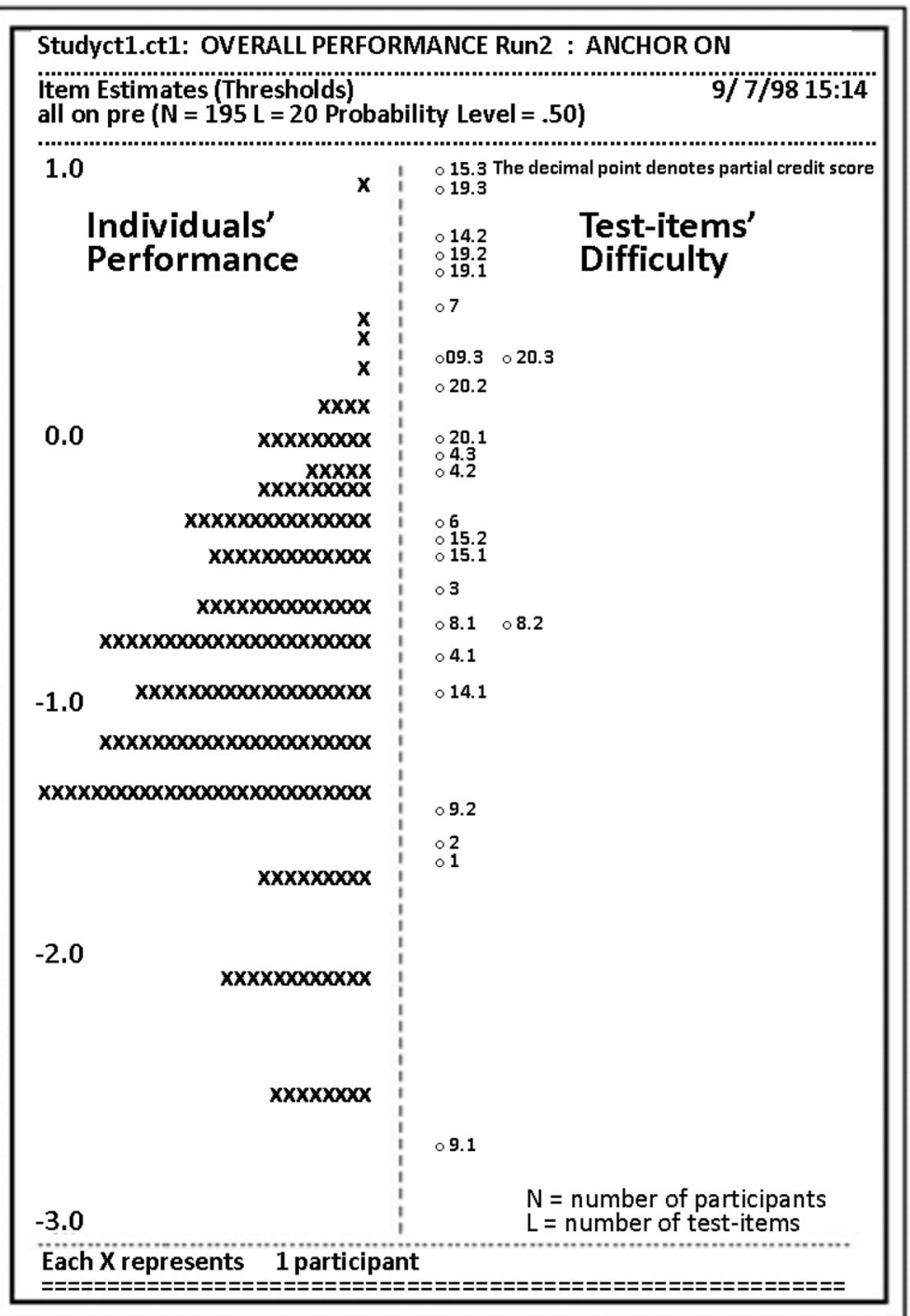

Fig. 7 QUEST variable map (McKay 2000a p.220). This figure shows how the QUEST estimate develops a uni-dimensional (logit) scale ( -3.0 to 1.0$)$ with equal intervals along each axis as it measures participants' performances and test-items together. The $x^{\prime} s$ on the left hand side of the figure represent an individual participant's performance with the total number of participants being 195. On the right hand side of the figure, is the difficulty rating of each test-item's performance (partial credit scored test-items have multiple entries: 8.1, 8.2 and 9.3, 20.2)

processing information (wholist/analytic), and instructional format, the 'wholists' performed better when given graphical metaphors than when receiving the text-only material. Moreover, when considering this CSA-dimension, the analytics also performed better with the graphical metaphors, although not as well as the wholists did. However, when considering the more detailed analysis of results relating to the combined CSA-dimensions, there was a more complex explanation. It was evident that when given a graphics-enhanced instructional strategy, particular combinations of the cognitive style construct had the potential to perform much better than others. In particular, the largest effect size for the integrated cognitive style groupings was accomplished by the wholist-imagers and analytic-verbalisers. While analytic-imagers perform 


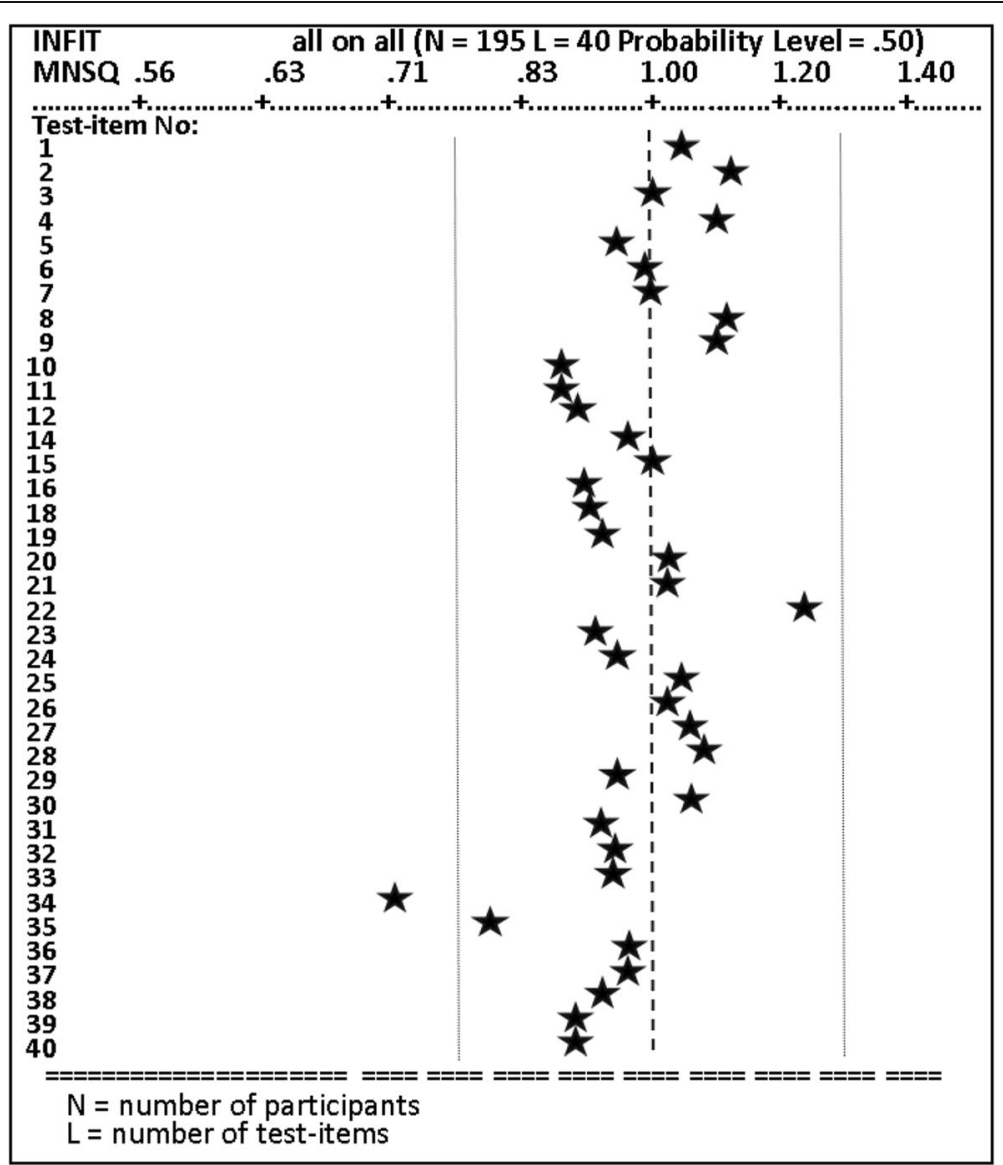

Fig. 8 QUEST fit map (McKay 2000a p.222). This figure shows the fit statistics (listed horizontally .56 to 1.40 is the infit mean square); the asterisks represent the magnitude of the fit statistic for the test-item on the same line. The test-items that fall between the two vertical dotted lines (thresholds .77 to 1.30) are considered acceptable; test-items to the left overfit (see test-item 34), indicating duplication or having limited contribution. Underfit test-items to the right of the threshold lines, measure something else and need rewording

poorly with the graphics format. This result was as expected from the exploratory study results (McKay 2000a) and confirmed in the final experiment.

Insofar as the consequence of gender in this study, there was a total of 98-males and 96- females in the final experiment. Of the males, 45-participants were given the textual metaphors, and 53-participants the graphical metaphors; whereas 56-females were given the former instructional treatment, and the remainder (40) graphical metaphors (McKay 2000a p.235). Figure 9 shows the relative distribution of these four-groups, with females given the graphical metaphors achieving the highest post-test distribution, and females with textual format having the lowest distribution. The two male groupings have similar distributions, resting between the two female distributions. It was therefore determined that the null hypothesis that was being tested indicated that gender would have no impact on the cognitive performance of one treatment group (instructional format/cognitive style compared to another), although females presented with graphical treatment performed better than females with the textual treatment. 


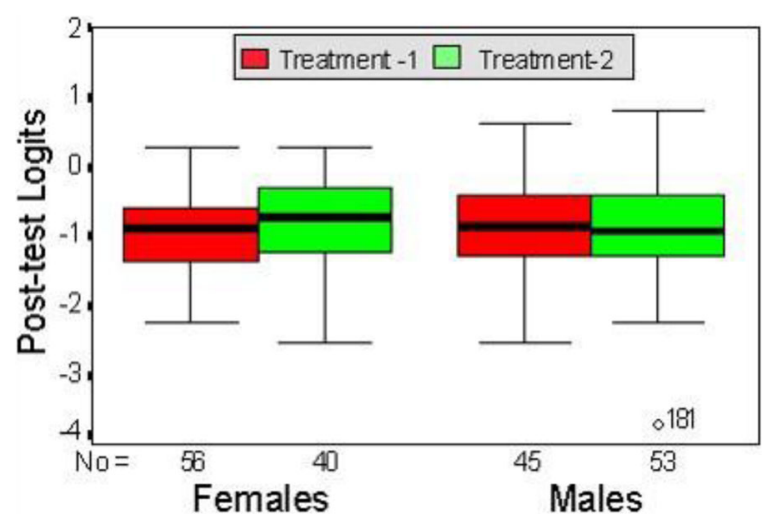

Fig. 9 Relative distribution - 4-groups (McKay 2000a p.235). This figure shows the relative distribution of the four-instructional treatment/gender groups (Treatment-1 textual metaphor and Treatment-2 graphical metaphors). Females given the graphical metaphors achieved the highest post-test distribution. Females with the textual metaphor format had the lowest distribution. The two male groupings had similar distributions, resting between the two female distributions

The final conclusions drawn from this research study indicated that, when describing the interactive effect of an instructional strategy on the means which individuals think of what they see (the 'verbaliser-imager' continuum):

1. verbalisers perform best when given an instructional format enhanced with graphical metaphors; and

2. some imagers may respond better with text-only material

Furthermore, when describing the interactive effects of the inherent mode of processing information and instructional format (the wholist-analytic continuum):

1. wholists perform better when given graphical metaphors than when receiving the text- only variety

2. analytics also performed better with the graphical metaphors, although not as well as the wholists

However, a more detailed analysis of results revealed a more complex explanation: it was evident that when given a graphics enhanced instructional strategy, particular combinations of cognitive style construct have the potential to perform much better than others.

In particular the largest effect size for the integrated cognitive style groupings was accomplished by the wholist-imagers and analytic-verbalisers. And, as expected from the exploratory study results, and equally confirmed in the final experiment, the analytic-imagers performed poorly with the graphics format (McKay 2000a).

\section{Summary}

This study provided an insight into how researchers can investigate the interactive effect of instructional strategies and cognitive style preferences on learning how to solve (in a digital sense) a particular business-related problem, and more specifically how to develop an algorithm that can be used to write a computer program. This study was 
also before the notions of big data implementations, yet researchers were commencing to identify the machine-dimensions of HCI (McKay 2008). One limitation of translating the McKay (2000a) work to the digital environment was the paper-based pedagogy/environment, whereas Mohamad (2012) moved the impact of this research into the online (or web-mediated) technologies.

\section{Study-3: Online instruction metaphors and cognitive style Introduction}

The Mohamad (2012) study extended the McKay (2000a) research to examine the interactive effects of web-mediated instructional strategies and cognitive preferences in the acquisition of introductory programming concepts in Malaysian universities.

Once again, and in keeping with the Sun (2018) stance on big data characteristics and the non-linear interrelationships through the 'technological framework,' this thesis extended the novel approach set by McKay (2000a) to deal with the cognitive assessment in a digital environment. Whereas the instructional strategies investigated by McKay (2000a) were paper-based, and involved graphical metaphors (McKay 1999a, 1999b), this study instead interrogated whether ICT elements such as: signals (or cues); interactive animation; navigational tools; words and graphics, influenced students' cognitive performance, and whether there were interactive effects of their cognitive preferences that may have contributed to the results. Like the paper-based Bagley (1990) and McKay (2000a) research, this empirical study examined the performance of novice-learners (or programmers) with different cognitive preferences, only this time the study used two web-mediated instructional strategies: 1) text-plus-textual format and 2) text-plus-graphical format. The research question under examination was: does the interactive effect of web-mediated instructional strategies and a learner's cognitive style preference affect the acquisition of introductory computer programming concepts?

The participants were second-year undergraduate students, in Malaysia, who were required to enrol in an Introductory Programming course as part of their educational programme commitment. The results suggested there is no clear evidence that cognitive preference played an important role in cognitive performance when learning from web-mediated instructional modules. However, it was observed that the analytic-verbalisers performed better when the instructional format they received matched their cognitive preferences. Because the participants were novice-learners, the influence of prior domain knowledge could not be ignored. The researcher knew the use of high-quality measurement tools to assess the effectiveness of web-mediated instructional strategies was important. The findings suggested guidelines on how to design web-mediated instruction for high-element interactivity knowledge domains such as the acquisition of computer programming concepts.

\section{Modified context for adoption online}

In selecting appropriate instructional strategies to be implemented in designing instructional systems for introductory programming concepts (and with appropriate permission), the treatment drew on the instructional programme employed by the McKay (2000a) work. The Mohamad (2012) study adapted the web-mediated learning content to focus 
on C++ instead of the original Bagley (1990) paper-based introductory Pascal programming language manuals, that were redesigned by McKay (2000a). Consideration was given to several factors such as the learner cognitive preferences, choice of delivery system, task complexity and technology (Merrill 2009). In considering the learner, the constructivist model assumes that learning occurs at the individual's level. Thus, Mohamad (2012) proposed that instruction should be designed to cater for individuals and not for groups of learners. Delivering instruction through web-mediated technology offers individuals the flexibility to access the instruction at their own pace and provides more time for reflection (Fetaji and Fetaji 2007). And so, in terms of learning-task complexity, it has been shown that an introductory programming concept is already complex enough for experienced-learners (as it involves high-element interactivity information) let alone for novice-learners (Garner et al. 2005); (Mohamad 2012). Given this level of complexity, the ID must take into consideration that the learners will need to have adequate prerequisite knowledge or skills to acquire more advanced skills or knowledge. Therefore, developing a unit of web-mediated instruction for the Mohamad (2012) study was based on the Gagné nine events of instruction (Gagné 1985). At that time, researchers were becoming interested in the effectiveness of the internet as an instructional device, for instance, the seven dimensions that contributed towards student success in web-mediated learning environments (Schrum and Hong 2002). These dimensions included access to tools, experience of technology, learning preferences, study habits and skills, goals and purposes, lifestyle factors and personal traits, and learner characteristics. In terms of a learner with different cognitive styles, they had similar but non-linear approaches towards learning in web-mediated environments (Chen 2010). Yet another study revealed that university students preferred structured and concept-based web-mediated instruction to a more traditional classroom approach (Yang and Tsai 2008). Moreover, the Mohamad (2012) study found that individual preference in web-based learning was influenced by an individual's ICT experiences. To further examine the effect of web-mediated instruction in terms of 'instructional strategies', the learning materials concentrated on both textual and multimedia formats.

The instructional topics within the web-mediated instructional system (WMIS) were developed to establish the possible advantages of integrating web-mediated interactivity with the textual and graphical instructional strategies. These modules were developed in two versions in the web-mediated environment according to the two McKay (2000a) paper-based treatment booklets that comprised textual and graphical metaphors. The Mohamad (2012) WMIS topics were represented as text-plus-textual metaphor (T1) and the text-plus-graphical metaphor (T2) instructional format. The learning content adapted the Pascal content of the McKay (2000a) instructional materials to the C++ content in a web-mediated instructional environment. The instruction was also developed according to the regular lesson plan implemented at the Malaysian university. Moreover, the newly developed Mohamad (2012) instructional strategies also included programming concepts and examples of $\mathrm{C}++$ programming (Deitel and Deitel 2008; Malik 2008; Zak 2008).

Although at the time the user-interface design was known to be one of the critical factors in successful web-mediated instruction, typically the instructional designers or educational software developers often neglected usability issues. Mohamad felt that if they did pay attention to usability issues, students relied on intuition and experience rather than 
theory-based models, so the Mohamad (2012) user-interface design took this issue into account. As such, it facilitated the learners to focus on the instructional strategies, thereby reducing the mental effort required for navigating their way through the modules (Lohr 2000).

Figure 10 shows the first screen of the Mohamad (2012 p.117) WMIS. This screen displayed knowledge navigation instruction or guidance on how to work through the instructional modules, thus making navigation of the topics/modules more possible by the menu-driven facility of the (knowledge) navigation buttons or hyperlinks.

A navigation button located at the bottom-right of the screen offered 'previous' and 'next' arrows, enabled the learners to move between topics. This type of button also indicated the learners' current location and the number of remaining topics. The instructional materials were always located on the white background area at the left side of the screen. The instructional materials were presented in dark text on a white background to facilitate ease of reading for learners who may have had colour perception deficiencies (McCracken and Wolfe 2004). To ensure that all information was seen in the one place, no scrolling of the screen was required. Therefore, to reduce extraneous cognitive load during learning, the instructional interface was designed consistently in terms of the usability and relating to the appearance, functionality and instructional ordering. Appearance meant using consistent 'visual elements' such as: layout; text style; colour and graphics throughout the instructional system. Functionality meant the same '(knowledge) navigation element' such as 'previous' and 'next' arrows on each screen which allowed the learners to navigate through the topics. Instructional ordering meant the screen organisation remained consistent throughout the WMIS, for instance the navigational button located at bottom-right of each screen (Galitz 2007).

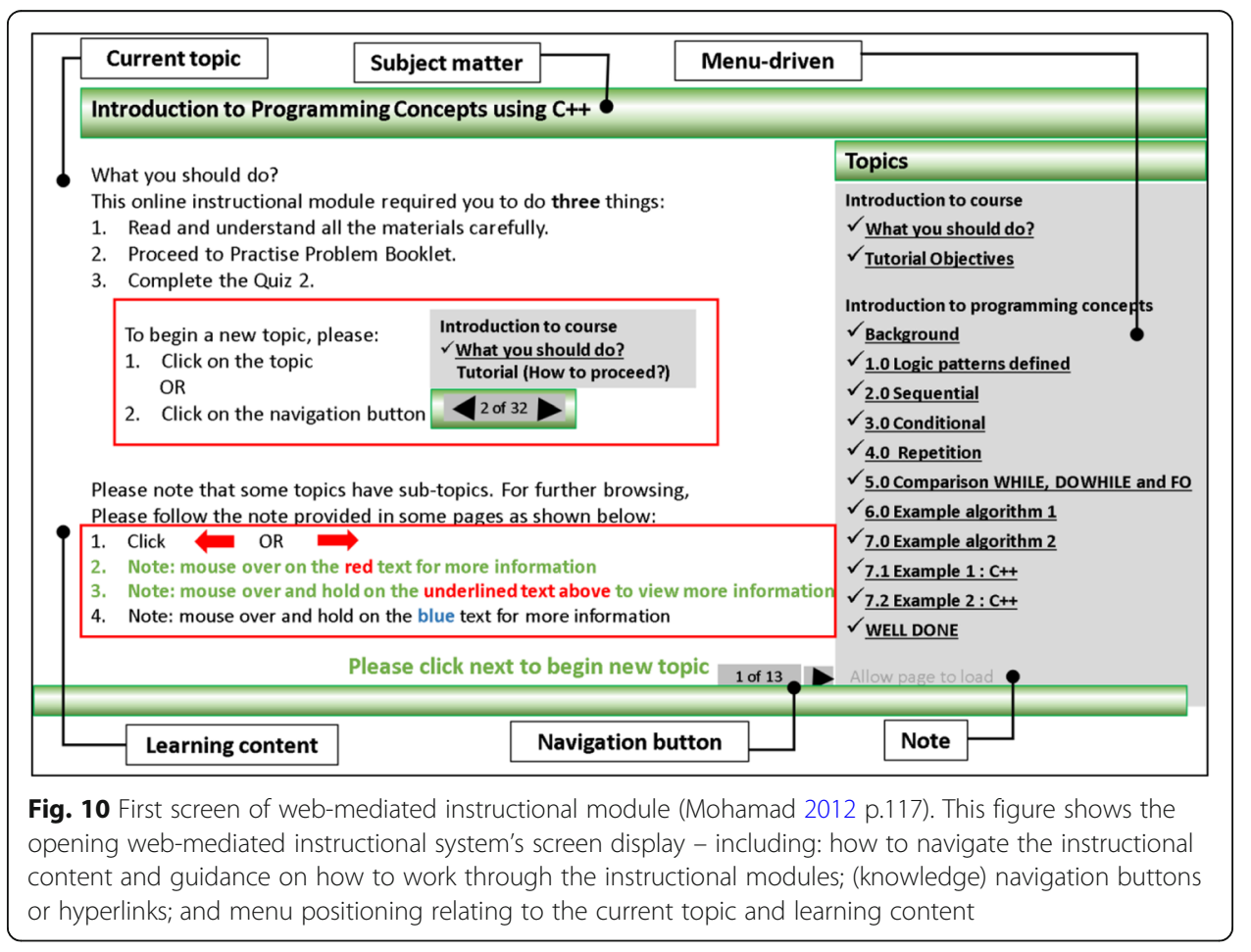




\section{Research design}

The Mohamad (2012) study involved a quasi-experimental $2 \times 4$ factorial research design combined with non-equivalent comparison or control group design that was manipulated to observe and analyse the variables. There were two independent variables: (a) 'instructional strategy, (T1) text-plus-textual treatment, and the (T2) text-plus-graphical treatment, and (b) 'cognitive preference' expressed as a CSA ratio (wholist-analytic/ verbaliser-imager). The researcher used the CSA ratio to split the participants with similar ratio results into the instructional treatments ( $\mathrm{T} 1$ or $\mathrm{T} 2$ ).

\section{Methodology}

A total of 399-participants were involved in this study. There were four stages involved in this experiment (see Fig. 11). The day-1 activity was carried out well before participants underwent the pre-test. The day-2 activities took place in the students' eighth week of their normal semester. Starting with a pre-test for prior domain knowledge, there were two (3-hour) sessions (T1 and T2); followed by the post-test. The quasi-experiment was conducted during this period because the participants were scheduled to learn the 'repetition control structure' topic in their normal classroom tuition.

The usual CSA screening test was conducted in stage-1 as pictured in Fig. 11. On day-2 of the experiment participants were given the paper-based questionnaire that comprised a 41-item pre-test (stage-2). Immediately after completing the pre-test questionnaire, the participants were required to access their WMIS treatment (stage-3). The duration to access the WMIS was limited to a one-hour period due to the fact that it was replacing their normal one-hour lecture during their tutorial session; and as such, they applied what they understood from the WMIS material into the online practice problem booklet. Stage-4 proceeded once they had completed the WMIS material. Therefore, the participants then received a 41-item post-test questionnaire. Because the

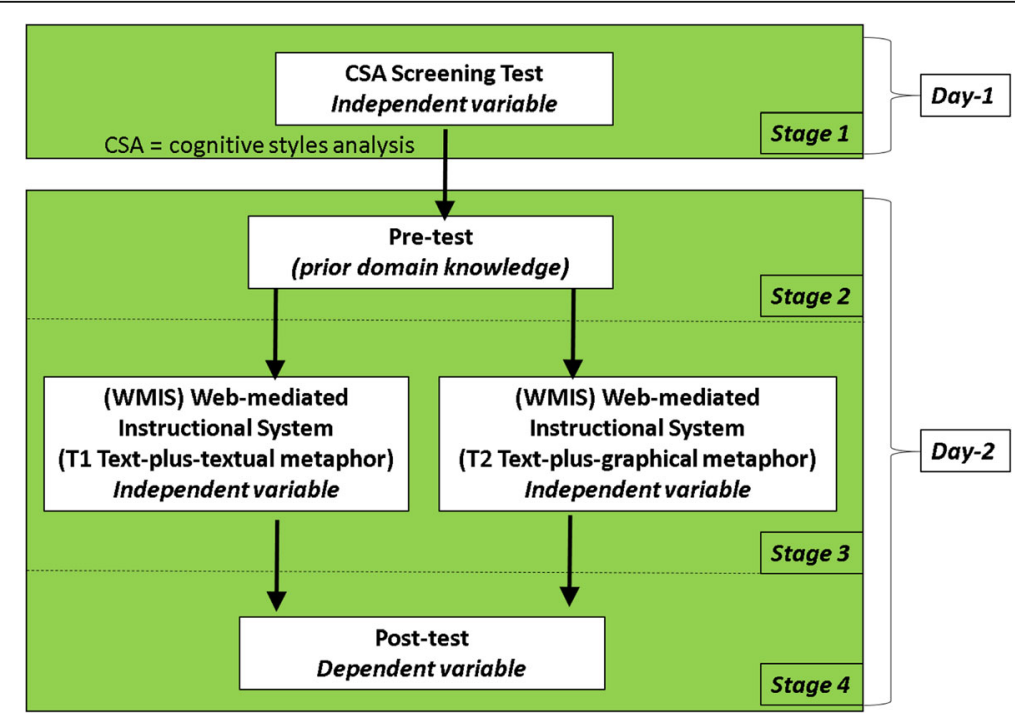

Fig. 11 Research schedule (Mohamad 2012 p.104). This figure shows the Research Schedule comprising the four research study stages: Stage-1, Day-1 involving the CSA screening test to allocate participants to their instructional treatment; Stage-2, Day2 involving the pre-test for prior domain knowledge; Stage-3 Day-2 involving the experiment; and Stage-4 Day-2 the post-test 
Rasch analysis does not cope well with absent data, it was important for the participants to provide their best answers. And so, in order to avoid incomplete responses for both the pre- and post-tests, they were guided by written and verbal explanations of the importance of completing all test-items.

\section{Data analysis}

There were 352-participants that successfully completed the pre- and post-tests. Participants with zero scores and perfect scores were excluded from the analysis. This was because the participants with zero scores provided no evidence of whether any learning had occurred. Similarly, the participants with perfect scores were unable to show how much learning had occurred (Izard 2005). In the final analysis, only 305 participants were counted for the effect size computation. The cognitive performance of students was measured using the difference between pre- (prlv) and post-test (polv) estimate logit-value (dlv) rather than just post-test results. The total of N value for the ICS group for T1 was calculated by adding $\mathrm{N}$ values of all ICS groups (wholist-verbaliser, $N=43$; wholist-imager, $N=$ 29; analytic-verbaliser, $N=48$ and analytic-imager, $N=44$ ), while the total of $\mathrm{N}$ value for $\mathrm{T} 2$ were 141. The graphical presentation in Fig. 12 displays the cognitive performance of integrated cognitive style (ICS) with the text-plus-textual (T1) and text-plus-graphical format (T2) based on average dlv.

Regardless of their cognitive preferences, the students performed better with the T1 than T2. There was an interesting finding with the ICS groups: the analytic-verbaliser

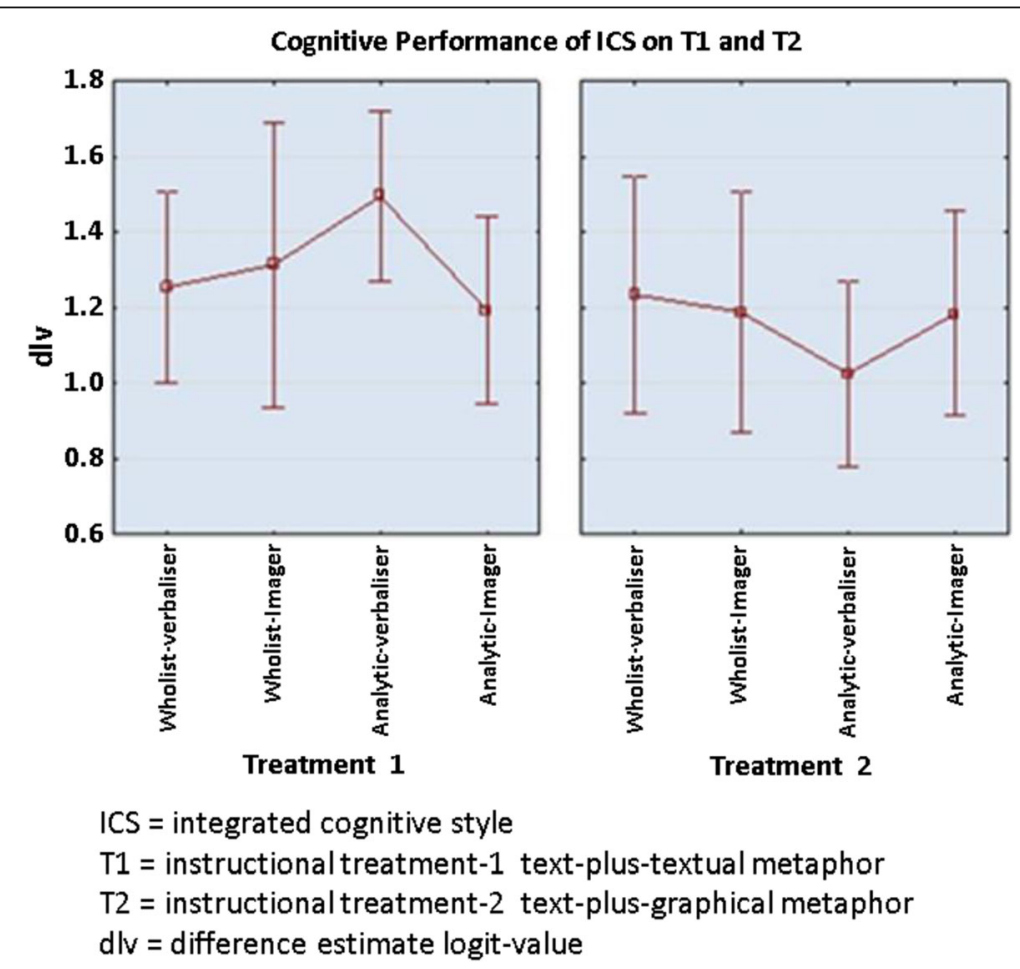

Fig. 12 Cognitive performance of ICS groups with T1 and T2 (Mohamad 2012 p.177). This figure shows the results in a graphical representation of the interactive nature of the cognitive performance of integrated cognitive style (ICS) wholist-verbaliser, wholist-imager, analytic-verbaliser, analytic-imager for the two instructional treatments: T1 (text-plus-textual metaphor) and T2 (text-plus-graphical format) based on average dlv 
group had a significantly higher average on cognitive performance with the T1 than T2. A medium effect size was observed $(d=0.62)$ (Cohen 1977); for the wholist-imagers, there was a negligible effect size observed $(\mathrm{d}=0.12)$. An even more trivial effect size was computed for the wholist-verbalisers and analytic-imagers $(\mathrm{d}=0.02$ and $\mathrm{d}=0.01$ respectively).

\section{Results}

An important practical effect was found with the analytic-verbalisers who performed better with the T1 (text-plus-textual metaphor) than with the T2 (text-plus-graphical metaphor). The analytic-verbaliser group was the top performer when given T1 (mean $\mathrm{dlv}=1.49$ ), yet their counterpart was the worst performer with $\mathrm{T} 2$ (mean $\mathrm{dlv}=1.03$ ). The top performer in T2 was a wholist-verbaliser (mean $\mathrm{dlv}=1.23$ ) group. The wholist-imagers performed slightly better in $\mathrm{T} 1$ (mean $\mathrm{dlv}=1.31)$ than $\mathrm{T} 2$ (mean $\mathrm{dlv}=1.19)$. Further, there was no practical important effect for wholist-verbaliser (mean dlv $\mathrm{T} 1=1.25$, mean dlv $\mathrm{T} 2=1.23$ ) and the analytic-imager (mean $\mathrm{dlv} \mathrm{T} 1=1.19$, mean $\mathrm{dlv} \mathrm{T} 2=1.18$ ) groups, on both treatments (T1 and T2), as they performed similarly with each treatment, yet the cognitive performance of the wholist-verbaliser group was better than the analytic-imagers on both instructional treatments.

\section{Discussion}

This paper has used three interrelated research studies to address the growing need for confirming whether those working with big data have the sufficient digital skills to cope (problem-solving abstract concepts; paper-based instructional metaphor format and cognitive style; and online instructional metaphors and cognitive style). These experiments showed the progression from the earlier methodological approach used for measuring proficiency between novice and experienced programmers with CTT (more commonly called traditional statistical measures), to adopting a more comprehensive unidimensional scale that empowers comprehension of human performance and test-item performance relative to each other. This latter methodology offers an effective tool for understanding individual differences in digital skill development.

The lessons learned from the Bagley (1990) results were that it is important to provide flexible training modules that afford different cognitive skill development pathways for novice and experienced people. The Bagley results confirmed two hypotheses: (1) that given a structured instructional pedagogy (forced step-by-step skill development), improved the learning of computer programming for people with no prior experiential knowledge of computer programming; and (2) that giving a discovery instructional pedagogy (allowing a self-selecting instructional pathway) improved learning for people possessing prior knowledge of computer programming. Moreover that when considering the interactive effect of instructional strategy and prior domain knowledge (experienced/novice) on performance outcomes - given the structured instructional format, the experienced learners did not perform as well.

In terms of managing big data (digital) tasks, it is important to know whether people have acquired problem-solving skills to solve abstract problems. Nevertheless, at the time of the Bagley study, the concept of big data had not yet surfaced. Instead, the term 'computer literacy' described the human-computer interaction (HCI). Researchers were mainly interested in the machine-dimension of the HCI (McKay 2008) examining peoples' capabilities expressed as arithmetic reasoning (problem-solving) abilities (Bagley 1990) to manage the computer operations. It took the advent of Web 2.0 and powerful 
computers to advance big data platforms that has refocused educational research on how to prepare effective pedagogies to enhance the digital skills development necessary to deal with big data characteristics.

The second study mentioned in this paper involved a much closer examination of the interactivity of preferred cognitive style and a paper-based instructional pedagogy on the Rasch measured performance outcomes. To answer the question targeted textual pedagogies were replaced with text-plus-textual metaphors (T1)/text-plus-graphical metaphors (T2). The study used the CSA ratio to split the research population according to the Riding and Cheema (1991) cognitive style continua (verbal-imagery (V:I), to depict a representation of information during thinking that may change according to the task at hand (Riding 1993); wholist-analytic (W:A), to depict mode of processing information, which Riding (1993) maintained is inherent and does not change).

To answer the research question (does the interaction of instructional format and cognitive style construct affect the acquisition of abstract programming concepts?) surprisingly, the verbalisers performed best when given the instructional format enhanced with graphical metaphors, and some imagers responded better with text-only material. This result was contra to the axiom that assumes verbal preferenced people perform best with textual pedagogies, while imagery preferenced people perform best with pictures.

Examining the interactive effects however of the W:A dimension revealed that the 'wholists' performed better with the graphical metaphors than the text only pedagogies. Yet, when considering the more detailed analysis of results involving the combined cognitive style analysis (CSA)-dimensions involving: wholist-verbaliser (W:V); analytic-verbaliser (A:V); wholist-imager (W:I); analytic-imager(A:I), the explanation was more complex. Consequently, using the Rasch measurement model, this research successfully showed that when given a graphics-enhanced pedagogy, particular combinations of the Riding and Cheema (1991) cognitive style construct had the potential to perform much better than others. Namely the largest effect size for the integrated (combined) cognitive style groupings were the W:I and A:V. This result was also confirmed in the final experiment where the A:I group performed poorly with the graphical pedagogy enhancements.

In terms of managing big data and implications arising from this research, are for the need to understand the complexity of how particular people will perform the necessary analytic problem solving tasks/operations more comfortably than others will.

The third study mentioned above in this paper extended the second (McKay 2000a), still examining the interactivity of preferred cognitive style but in a digital (online) instructional pedagogy, again using the Rasch measured performance outcomes. This study interrogated the ICT pedagogical elements: text-plus-textual metaphor (T1), or text-plus-graphical metaphors (T2). These treatments formed the basis of an investigation on whether the interactive effects of the independent variables (the participants' CSA ratio and instructional treatment) had contributed to the results. In this case the research question was: does the interactive effect of web-mediated instructional strategies and a learner's cognitive style preference affect the acquisition of introductory computer programming concepts?

The research question was answered successfully using the combined CSA ratio. Importantly, the A:V group performed better with the $\mathrm{T} 1$ than with the $\mathrm{T} 2$. The A:V group 
was the top performing group when given T1, yet given T2 they were the worst. The top performing group with T2 was the W:V; while the W:I group performed slightly better in T1 than T2. Further, there was no important effect for W:V and the A:I groups on both $\mathrm{T} 1$ and T2, as they performed similarly with each treatment, yet the cognitive performance of the W:V group was better than the A:I group on both instructional treatments.

These results further emphasise the importance of knowing whether particular people will perform the necessary analytic problem solving tasks/operations more comfortably than others will, when required to manage big data.

\section{Conclusion}

The term 'big data' means many things to many people, so we say it is something that the average researcher should not be apprehensive to investigate. One way to enter this relatively newly-labelled field is to concentrate on managing the development of digital skills that are involved in maintaining big data platforms. And so, to determine correctly an individual's digital skills' level is made possible by systematically following the McKay (2000a) or the Mohamad (2012) methodology. Such research projects can achieve similar measurable and valid analysis results that correctly determine an individual's digital skills level. Firstly, one must define the knowledge levels within the study domain, and then design a test instrument to capture the participant's skills. Then a structured scoring rubric must be developed to scale participant achievement on the (digital skills) test. The instrument must first be validated, with the poorer test-items (too easy, too hard, or poorly worded such that participants cannot understand what is expected) either removed, or modified and re-validated. Once the instrument is fully validated then it can be implemented. This validated test can be used as a one-off skills level bench-mark. However, to measure the effectiveness of an instructional programme, it is recommended that the methodology involves a pre-test to measure participants' prior domain knowledge, followed by the instructional treatment, and then a post-test to measure what they know (or do not know) after the treatment. The participant performance can then be measured as the difference in QUEST scores between the pre-test and the post-test. The internal consistency of the Rasch IRT model and the statistical variables generated by packages such as the QUEST Interactive Test Analysis System and a newer version called RU2030 (Andrich et al. 1997-2005) to allow the researcher to produce quantitative research results from limited data and fewer participants. Finally, a Cohen statistical power analysis can be used to determine the magnitude of effect of different treatments or different participant characteristics on performance outcomes according to McKay and Izard (2015).

This paper takes the view initiated by Sun (2018) to convey that managing/working in a big data environment involves a plethora of high-level digital skills that will change according to the cognitive preferences of each individual and the task at hand. Therefore discerning what people know and what they do not know is imperative. Otherwise, endless mess will result, with ill-informed people blaming 'the data', and projects not realising their potential.

Abbreviations

A:l: analytict:imager cognitive style dimension; A:V: analytic:verbaliser cognitive style dimension; ANOVA: Analysis of variance; CSA: cognitive styles analysis; CTT: classical test theory; d: effect size; dlv: difference logit-value; $\mathrm{HCl}$ : humancomputer interaction; HE: higher education; ICS: integrated cognitive style; ICT: information communications technology; ID: instructional design; IRT: item response theory; IS: information systems; IT: information technology; 
polv: post-test estimate logit-value; prlv: pre-test estimate logit-value; T1: Treatment-1 (text-plus-textual metaphor); T2: Treatment-2 (text-plus-graphical metaphor); W:I: wholist:imager cognitive style dimension; W:V: wholist:verbaliser cognitive style dimension; WAIS: Weschsler Adult Intelligence Scale; WMIS: web-mediated instructional system

\section{Acknowledgements}

The authors wish to thank Professor Carole Bagley for material pertaining to the first study.

\section{Availability of data and materials}

Requests for data and materials will be evaluated on a case-by-case basis.

\section{Authors' contributions}

EMcK was responsible for the writing of this paper and supply of the second study data and materials. MBM supplied the material for the third study and proof reading of the draft submission. Both authors read and approved the final manuscript.

\section{Competing interests}

The authors declare that they have no competing interests.

The authors have no financial competing interest. Nor do they hold any stocks or shares in an organisation that may in any way gain or lose financially from the publication of this manuscript, either now or in the future? Authors also do not hold or are currently applying for any patents relating to the content of the manuscript? Nor have they received reimbursements, fees, funding, or salary from an organisation that holds or has applied for patents relating to the content of the manuscript.

We also confirm there are no non-financial competing interests (political, personal, religious, ideological, academic, intellectual, commercial or any other) to declare in relation to this manuscript.

\section{Publisher's Note}

Springer Nature remains neutral with regard to jurisdictional claims in published maps and institutional affiliations.

\section{Author details}

${ }^{1}$ RMIT University, School of Business Information Technology and Logistics, GPO Box 2476, Melbourne, VIC 3000, Australia. ${ }^{2}$ Department of Engineering Education, Faculty of Technical and Vocational Education, Universiti Tun Hussein Onn Malaysia, 86400 Parit Raja, Batu Pahat, Johor, Malaysia.

Received: 28 November 2017 Accepted: 25 April 2018

\section{Published online: 18 May 2018}

\section{References}

Adams, RJ, \& Khoo, S-T (1996). QUEST:The Interactive Test Analysis System (Vol. 1). Melbourne: Australian Council for Educational Research

Alsharif, M, \& Nordin, R. (2017). Evolution towards fifth generation (5G) wireless networks: Current trends and challenges in the deployment of millimetre wave, massive MIMO, and small cells. Telecommunication Systems, 64(4), 617-637.

Alwi, A, \& McKay, E. (2012). Consideration for cognitive preferences to enhance effective HCl in online exhibits. International Journal of Computer Information Systems and Industrial Management Applications (IJCISIM), ISSN:2150-7988, 3, 472-479.

Andrich, D, Sheridan, B, Luo, G (1997-2005). RUMM2020. Perth: RUMM Laboratory.

Bagley, CA (1990). Structured versus discovery instructional formats for improving concept acquisition by domainexperienced and domain-novice adult learners. Minnesota: partial fulfillment of the requirement for the Degree of Doctor of Philosophy.

Bakkar, MN (2016). An investigation of mobile healthcare (mHealthcare) training Design for Healthcare Employees in Jordan. Melbourne: RMIT University, School of Business Information Technology and Logistics https://researchbank.rmit.edu. au/view/rmit:161776/Bakkar.pdf.

Barefah, A, \& McKay, E (2016). Evaluating the design and development of an adaptive e-tutorial module: A Rasch measurement approach, Paper presented at the educational technologies 2016 (ICEduTech) (). Melbourne: RMIT University https://eric.ed.gov/?id=ED571591.

Bond, TG, \& Fox, CM (2015). Applying the Rasch model: Fundamental measurement in the human services (3rd edition). New York and London: Routledge, Taylor \& Francis.

Chen, L. (2010). Web-based learning programs: Use by learners with various cognitive styles. Computers \& Education, 54(5), 1028-1035.

Cohen, J (1977). Statistical Power Analysis for the Behavioral Sciences (revised ed.). New York: Academic Press.

Deitel, P.J, \& Deitel, H. M (2008). C++ how to program (6 ed.)

Digital Skills Academy launches online degree in integrated digital technology, business, design. (2015). https://www. thedigitalhub.com/companydirectory/digital-skills-academy/

Farrington, C. (2016). Big data meets human health. Science, 353(6296), 227.

Fetaji, B., \& Fetaji, M. (2007). E-Learning indicators methodology approach in designing successful E- learning. Paper presented at the Paper presented at the International Conference on Information Technology Interfaces, Cavtat, Croatia.

Gagné, RM (1985). The conditions of learning: And the theory of instruction, (4th ed., ). NY: Holt/Rinehart/Winston. Galitz, WO (2007). The essential guide to user interface design: An introduction to GUI design principles and techniques, (3rd ed., ). Indianapolis: Wiley. 
Garner, S., Haden, P. \& Robins, A. (2005). My program is correct but it doesn't run: A preliminary investigation of novice programmers problem. Paper presented at the Paper presented at the Australia Conference on Computing Education, Newcastle, Australia.

Griffin, P, \& Nix, P (1991). Educational assessment and reporting: A new approach. Victoria: Harcourt Brace.

Hartley, RJ. (2003). An interactive computer-based simulation environment for supporting and developing complex decision-making skills. E.McKay \& P.Kommers (eds). International Journal of Continuing Engineering Education and Life-Long Learning, 3((13) 3/4), 212-231.

Hepburn, H. (2013). Tune into a digital skills academy. The Times Educational Supplement Scotland, 2302(25) https:// search-proquest-com.ezproxy.lib.rmit.edu.au/docview/1321297603?accountid=13552.

Izard, J. (1999). Some potential difficulties in educational research studies (and how to avoid them), paper written for the third elementary education project, Philippines.

Izard, J (2005). Trial testing and item analysis in test construction - Module-7. In KN Ross (Ed.), Quantitative research methods in educational planning, (p. 84). Paris: International Institute for Educational Planning.

Lohr, LL. (2000). Designing the instructional interface. Designing the instructional interface. Computers in Human Behavior, 16(2), 161-182.

Malik, DS (2008). C++ programming: Program design including data structures, (4th ed., ). New York: Clifton Park.

Marr, B (2016a). Big data for small business. Chichester: Wiley.

Marr, B (2016b). Big data in practice: How 45 successful companies used big data analytics to deliver extraordinary results. Chichester: John Wiley \& Sons, Ltd.

Mat-Jizat, JE (2012). Investigating ICT-literacy assessment tools: Developing and validating a new assessment instrument for trainee teachers in Malaysia. Melbourne: RMIT University, School of Business Information Technology and Logistics http://researchbank.rmit.edu.au/view/rmit:160385/Mat_Jizat.pdf.

McCracken, DD, \& Wolfe, RJ (2004). User-centered website development: A human-computer interaction approach. Upper Saddle River: Prentice Hall.

McKay, E. (1999a). Exploring the effect of graphical metaphors on the performance of learning computer programming concepts in adult learners: A pilot study. Educational Psychology, 19(4), 471-487.

McKay, E. (1999b). An investigation of text-based instructional materials enhanced with graphics. Educational Psychology, 19(3), 323-335.

McKay, E (2000a). Instructional strategies integrating the cognitive style construct: A meta-knowledge processing model (contextual components that facilitate spatial/logical task performance). Geelong: Com. Sci. \& Info. Sys.(Ph. D. thesis Deakin University.

McKay, E. (2000b). Measurement of cognitive performance in computer programming concept acquisition: Interactive effects of visual metaphors and the cognitive style construct. Journal of Applied Measurement, 1(3), 257-286.

McKay, E (2008). The Human-Dimensions of Human-Computer Interaction: Balancing the HCl Equation (1 ed. Vol. 3). Amsterdam: IOS Press.

McKay, E, \& Izard, JF (2015). Evaluate online training effectiveness: Differentiate what they do and do not know, Paper presented at the 8th international conference on ICT, society and human beings 2015 (multi conference on computer science and information systems - MCCSIS), las Palmas de gran Canaria (pp. 35-44).

Melendez, C. (2015). Predictive analytics: Where big data and messy humans meet. InfoWorld.com (May 28). https:// www.infoworld.com/article/2922179/big-data/predictive-analytics-where-big-data-and-messy-humans-meet.html

Merrill, DM (Ed.) (2009). First principles of instruction. Instructional design theories and models: Building a common knowledge base, (vol. III). NY: Routledge.

Merrill, MD, Tennyson, RD, Posey, LO (1992). Teaching concepts: An instructional design guide, (2nd ed., ). Englewood Cliffs: Educational Technology Publications.

Mohamad, M (2012). The effects of web-mediated instructional strategies and cognitive preferences in the Acquisition of Introductory Programming Concepts: A Rasch model approach. Melbourne: Doctoral Thesis RMIT University, School of Business Information Technology and Logistics https://researchbank.rmit.edu.au/view/rmit:160201/Mohamad.pdf.

Riding, R (1993). A Trainer's guide to learning design: Learning methods project report, (p. 47). Birmingham: Assessment Research Unit, University of Birmingham, UK.

Riding, R, \& Cheema, I. (1991). Cognitive styles - an overview and integration. Educational Psychology, 11(3\&4), 193-215.

Riding, RJ, \& Rayner, S (1998). Cognitive styles and Learning Strategies. London: Fulton.

Schöch, C. (2013). Big? Smart? Clean? Messy? Data in the humanities. Journal of Digital Humanities, 2(3), 2-13(3) 2-13. https://hal.archives-ouvertes.fr/hal-00920254.

Schrum, L, \& Hong, S. (2002). Dimensions and strategies for online success: Voices from experienced educators. Journal of Asynchronous Learning Environment, 6(1), 57-67.

Sun, Z. (2018) 10 Bigs: Big data and its ten big characteristics. https://www.researchgate.net/publication/322592851_10_ Bigs_Big_Data_and_Its_Ten_Big_Characteristics

Tambe, P. (2014). Big data investment, skills, and firm value. Management Science, 60(6), 1452-1469.

Tennyson, RD, \& Bagley, CA (1991). Structured versus constructed instructional strategies for improving concept acquisition by domain-experienced and domain-novice learners. Illinois: Paper presented at the Annual Meeting of the American Educational Research Association.

Van Laar, E, Van Deursen, A, Van Dijk, J, De Haan, J. (2017). The relation between 21st-century skills and digital skills: A systematic literature review. Computers in Human Behavior, 72, 577-588.

Wu, M., \& Adams, R. (2007). Applying the Rasch model to psycho-social measurement: A practical approach.

Yang, F, \& Tsai, C. (2008). Investigating university student preferences and beliefs about learning in the web-based context. Computers \& Education, 50(4), 1284-1303.

Zak, D (2008). An introduction to programming with C++ (5 ed.). Boston: Thomson Course Technology. 